\title{
Влияние коммюнотарной идеологии свободного программного обеспечения на формирование нравственно- этической культуры, жизненное и личностное самоопределение обучающегося
}

\author{
А.Ю. Федосов ${ }^{1}$, М.В. Маркушевич ${ }^{2}$ \\ ${ }^{1}$ Российский государственный социальный университет, \\ ${ }^{2}$ ГБОУ города Москвы «Школа № 1352» \\ alex_fedosov@mail.ru, mihaell1@yandex.ru
}

\section{Аннотация}

В работе обсуждается коммюнотарная идеология свободного программного обеспечения как источник построения образовательного процесса, направленного на решение задач жизненного и личностного самоопределение обучающихся, формирования ценностно-смысловой ориентации учащихся, ориентации в социальных ролях и межличностных отношениях, личностной мотивации к учебной деятельности.

Авторами обосновывается тезис о том, что основой для формирования компонентов нравственно-этической культуры, жизненного и личностного самоопределения обучающегося может выступать коммюнотарная идеология свободного программного обеспечения, раскрыты преимущества использования свободного программного обеспечения в образовательном процессе для решения задач духовнонравственного воспитания.

В статье представлены пути формирования нравственно-этической культуры, жизненного и личностного самоопределения обучающихся: на основе анализа характерных свойств свободного программного обеспечения выявлены возможности формирования у обучающихся умений выделять нравственный аспект поведения и соотносить поступки и события с принятыми этическими принципами, навыков выбора предпочитаемой сферы профессиональной деятельности и вхождения в то или иное профессиональное сообество, ориентации в социальных ролях и межличностных отношениях, навыков выбора инструмента для решения учебных и профессиональных задач и направленность на сотрудничество и бескорыстную взаимопомощь другим обучающимся в их освоении и применении.

Ключевые слова: свободное программное обеспечение, коммюнотарность, нравственно-этическая культура, жизненное самоопределение, личностное самоопределение, мотивация к учебной деятельности.

Библиографическая ссылка: Федосов А.Ю., Маркушевич М.В. Влияние коммюнотарной идеологии свободного программного обеспечения на формирование нравственно-этической культуры, жизненное и личностное самоопределение обучающегося // Информационное общество: образование, наука, культура и технологии будущего. Выпуск 4 (Труды XXIII Международной объединенной научной конференции «Интернет и современное общество», IMS-2020 (сборник научных статей). - СПб: Университет ИТМО, 2020. С. 92-100. DOI: $10.17586 / 2587-8557-2020-4-92-100$ 


\section{Введение}

В современном обществе все большую остроту приобретает проблема морали и этической культуры подрастающего поколения. Нравственно-этическая культура выступает способом постижения действительности, является направляющей силой к вершинам морали, человеческого духа, осознанию ценности человеческой жизни. Это актуализирует необходимость перехода от авторитарных к гуманистическим принципам воспитания подрастающего поколения, утверждение ценностей добра, справедливости, чести, достоинства, совести, долга, ответственности.

Поэтому особое значение приобретает воспитание нравственно-этической культуры обучающихся, которое предполагает формирование ценностного отношения к себе, окружающим, Родине, природе. Это обуславливает совершенствование содержания, форм, методов нравственного и этического воспитания обучающихся. Проблема нравственного и этического воспитания нашла воплощение в Законе «Об образовании в Российской Федерации», в Концепции духовно-нравственного развития и воспитания личности гражданина России, Стратегии развития воспитания в Российской Федерации на период до 2025 года $[1 ; 2 ; 3]$.

В аспекте рассмотрения актуальных проблем модернизации образования, в том числе в предметной области «Математика и информатика», авторам хотелось бы рассмотреть проблематику решения крайне значимых для современной школы и Вуза задач жизненного и личностного самоопределения обучающихся и предложить некоторые новые пути для успешного решения данных задач.

Можно с уверенностью сказать, что сегодня одной из самых сложных педагогических проблем является личностная мотивация обучающихся к учебной деятельности. Чаще всего это связано с несформированностью у определённой части обучающихся смысловой связи между процессом обучения и конечными перспективами или продуктом обучения. Таким образом, они не воспринимают и сам процесс обучения, и его результат как ценность, что приводит к тяжелой деформации всего учебно-воспитательного процесса.

Очевидно, что ответственность за формирование той части аксиосферы обучающихся, которая имеет отношение к осознанию ими личностной ценности образования, лежит в существенной своей части на преподавателе (учителе). Для решения данной нетривиальной задачи современный педагог должен предложить учащимся или студентам некую универсальную систему ценностей, усвоив которую обучающиеся могли бы оценить и ценность получаемого ими образования. Сложность поставленной задачи заключается в том, что ввиду современного релятивизма в нашем обществе в решении смыслообразующих, мировоззренческих задач, крайне проблематично предложить некую универсальную систему ценностей обучающихся. «В релятивизме отсутствует единая абсолютная истина, он оправдывает и уравнивает различные точки зрения на личную нравственность, утверждая, что, сколько людей - столько мнений об истине. При таком подходе главное место в привитии этических норм и нравственных понятий начинает занимать воспитание индивида в духе соблюдения достигнутых договоренностей (законов), то есть соответствующих нравственных норм. В этом случае цель воспитания сводится к осознанию человеком ценности человеческого общежития, существование которого возможно лишь при наличии морали» [4, с.31].

Однако мы всегда должны помнить, что основным смыслом и целью современного образования является развитие личности учащегося, что, в частности, в Фундаментальном ядре содержания общего образования предложено осуществлять через формирование универсальных учебных действий, которые полагаются в качестве инвариантной основы учебно-воспитательного процесса. Именно формирование универсальных учебных действий должно обеспечить способность учащегося $\kappa$ саморазвитию и самосовершенствованию путем сознательного и активного присвоения нового социального опыта, что можно кратко сформулировать как умение учиться [5]. 
Наиболее значимым в контексте личностной ориентации современного российского образования является блок личностных универсальных учебных действий. Но именно формирование данного типа универсальных учебных действий стало на современном этапе наиболее проблематичным для школьного учителя в плане выбора соответствующего содержания образования, приемов, методов, форм обучения по причинам некоторого релятивизма в области существующих систем ценностей.

Личностные универсальные учебные действия включают жизненное, личностное, профессиональное самоопределение; действия смыслообразования и нравственноэтического оценивания, реализуемые на основе ценностно-смысловой ориентации учащихся (готовности к жизненному и личностному самоопределению, знания моральных норм, умения выделить нравственный аспект поведения и соотносить поступки и события с принятыми этическими принципами); ориентации в социальных ролях и межличностных отношениях [5].

Основой для формирования компонентов нравственно-этической культуры, жизненного и личностного самоопределения обучающегося, сконцентрированных в личностных универсальных учебных действиях, с точки зрения авторов, может выступать коммюнотарная идеология свободного программного обеспечения.

В терминологии Н.А. Бердяева коммюнотарность - (от лат. communitas - общность, общение) - термин, подразумевающий персоналистическое, духовное, на основе свободы, любви, искренности, братства, межчеловеческое общение, опосредованное Богом [6].

Насколько же идеология свободного программного обеспечения коммюнотарна? Можно ли заявлять именно об «идеологии» в отношении программного обеспечения и какова она для свободного программного обеспечения?

Авторы считают, что если речь идёт о совокупности системных упорядоченных взглядов, выражающих интересы различных социальных классов и других социальных групп, на основе которых вырабатывается концепция того или иного типа программного обеспечения, то можно говорить, что это в полной мере соответствует определению термина «идеология» [7].

Свободное программное обеспечение разрабатывается программистами-энтузиастами, объединенными в свободные сообщества, любой пользователь может свободно воспользоваться данным программным обеспечением, установить его на свой компьютер и использовать неограниченный период времени, передавать дистрибутив другим пользователям, просматривать программный код, вносить в него изменения и далее распространять в изменённом виде. Техническая поддержка свободного программного обеспечения обычно осуществляется на форумах, где опытные разработчики и пользователи добровольно помогают новичкам освоить используемое ими программное обеспечение, разобраться в его тонкостях и особенностях настройки.

Таким образом, продукт творческого интеллектуального труда коллектива единомышленников свободно передается всем заинтересованным в нём людям. «Творческий акт есть не только движение вверх, но и движение к другому, к миру, к людям» [8]. Именно этой ориентацией на человека свободного, творческого характеризуется идеология открытого программного обеспечения.

В качестве преимуществ использования свободного программного обеспечения в образовательном процессе в духовно-нравственном отношении выступают, в частности: возможность формирования у обучающихся «ментальности квалифицированного члена современного информационного общества, различающего наличие потенциальных информационных угроз и готового противостоять им» [9, с. 41]; возможность раскрытия творческих способностей личности обучающегося «путем освобождения его от скрытых духовных деформаций, обусловленных наличием навязанных и многократно закрепленных неоптимальных алгоритмов действий в тех или иных ситуациях» $[9$, с. 43$]$. 
Таблица 1. Пути формирования компонентов нравственно-этической культуры, жизненного и личностного самоопределения обучающегося

\begin{tabular}{|c|c|c|}
\hline $\begin{array}{l}\text { № } \\
\text { п/ா }\end{array}$ & $\begin{array}{c}\text { Свойства свободного программного } \\
\text { обеспечения }\end{array}$ & $\begin{array}{c}\text { Пути формированию компонентов } \\
\text { нравственно-этической культуры, } \\
\text { жизненного и личностного } \\
\text { самоопределения обучающегося }\end{array}$ \\
\hline 1. & $\begin{array}{l}\text { Свободное программное } \\
\text { предоставляется, как правило, на бесплатной } \\
\text { основе, таким образом, пользователь не чувствует } \\
\text { себя в роли классического потребителя на рынке } \\
\text { товаров и услуг, где в нём заинтересованы только } \\
\text { как в плательщике. То есть пользователь } \\
\text { выступает полноценным партнером, который } \\
\text { бесплатно использует программное обеспечение, } \\
\text { а также может участвовать в его распространении, } \\
\text { развитии и оказывать помощь другим } \\
\text { пользователям. } \\
\text { В случае использования лицензии на свободное } \\
\text { программное обеспечение, которая предоставляет } \\
\text { получателям права на модификацию и повторное } \\
\text { распространение на основе принципа } \\
\text { «наследования» прав, пользователь выступает как } \\
\text { автор интеллектуального продукта и сохраняет } \\
\text { авторство, но при этом может распространять } \\
\text { программное обеспечение, а также гарантировать, } \\
\text { что и пользователи всех производных программ } \\
\text { получат вышеперечисленные права. }\end{array}$ & 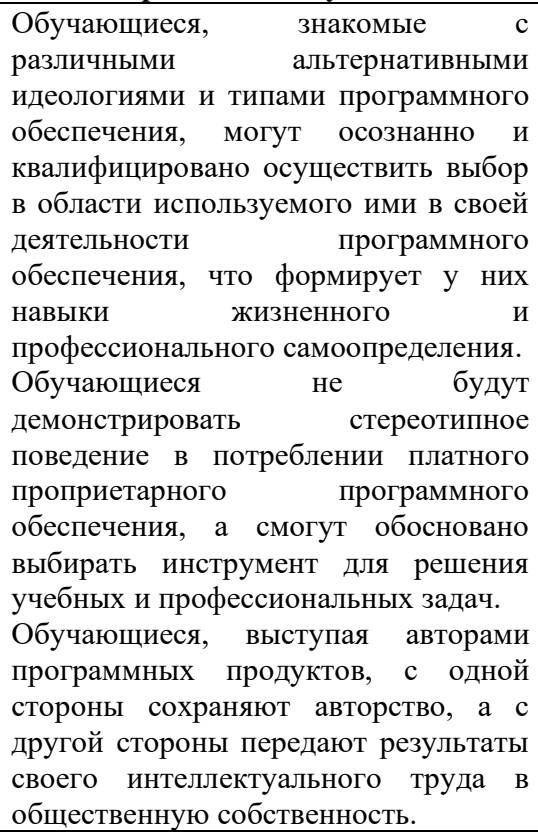 \\
\hline 2. & 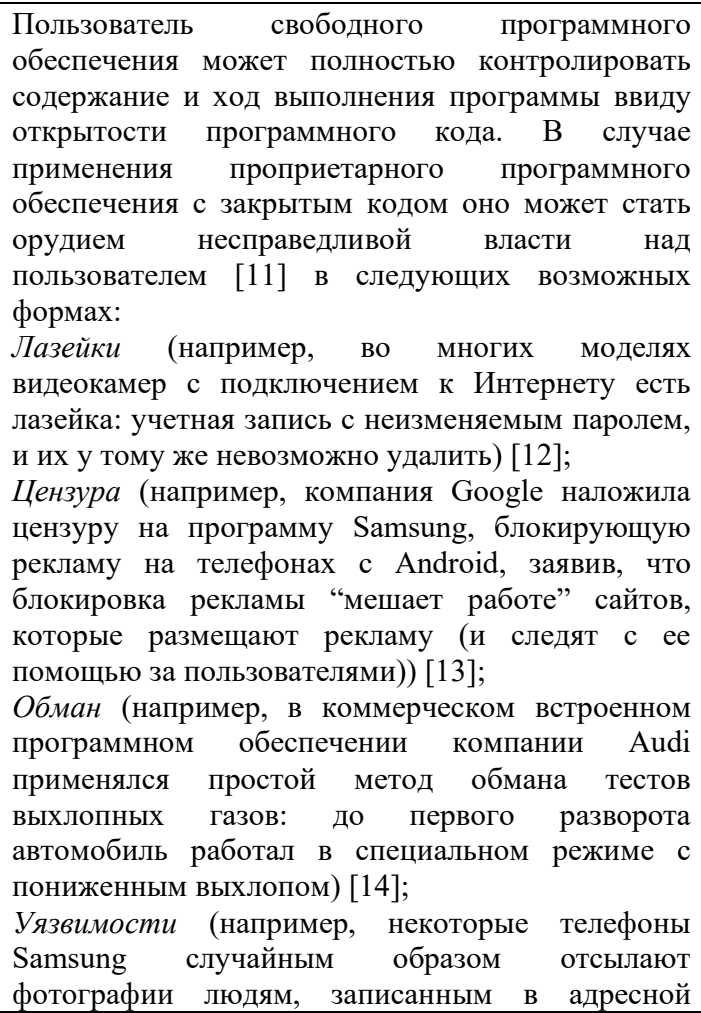 & 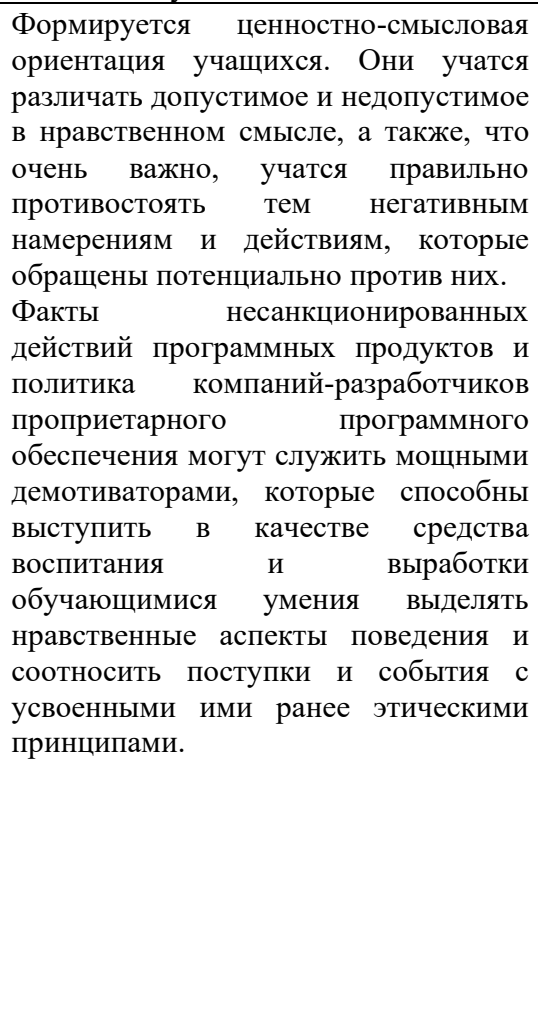 \\
\hline
\end{tabular}




\begin{tabular}{|c|c|c|}
\hline $\begin{array}{l}\text { № } \\
\text { ПI/II }\end{array}$ & $\begin{array}{c}\text { Свойства свободного программного } \\
\text { обеспечения }\end{array}$ & $\begin{array}{c}\text { Пути формированию компонентов } \\
\text { нравственно-этической культуры, } \\
\text { жизненного и личностного } \\
\text { самоопределения обучающегося }\end{array}$ \\
\hline & $\begin{array}{l}\text { книжке владельца) [15]; } \\
\text { Саботаж } и \text { скрытое давление на потребителя } \\
\text { (например, компания Microsoft прекратила } \\
\text { поддержку Windows 7, в том числе и } \\
\text { компьютерах, оснащенных } \\
\text { процессорами) [16]. }\end{array}$ & \\
\hline 3. & 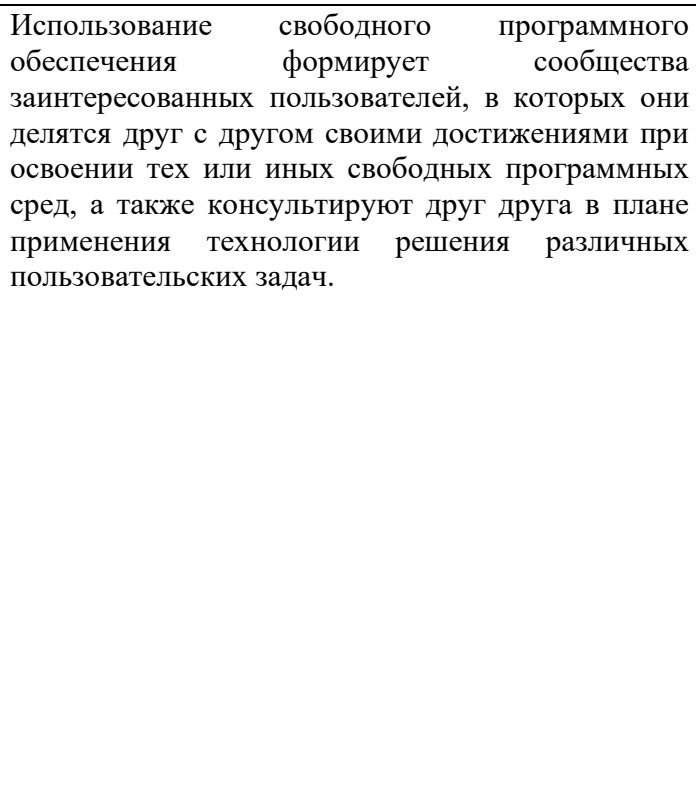 & 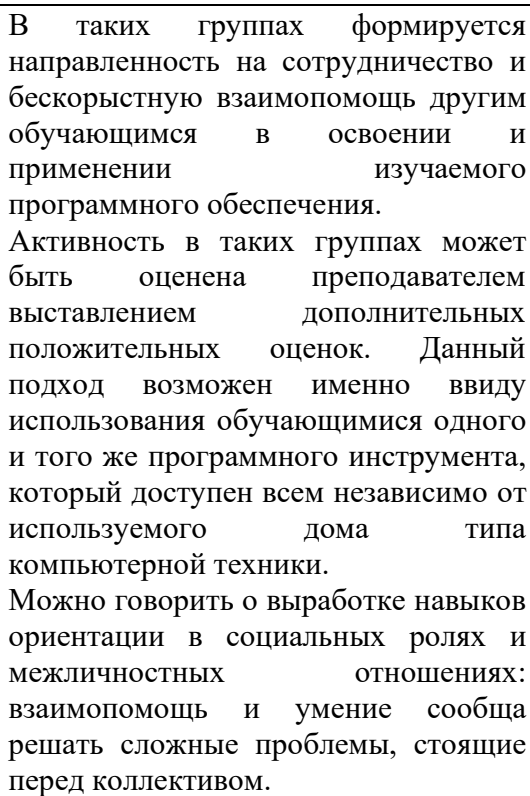 \\
\hline 4. & 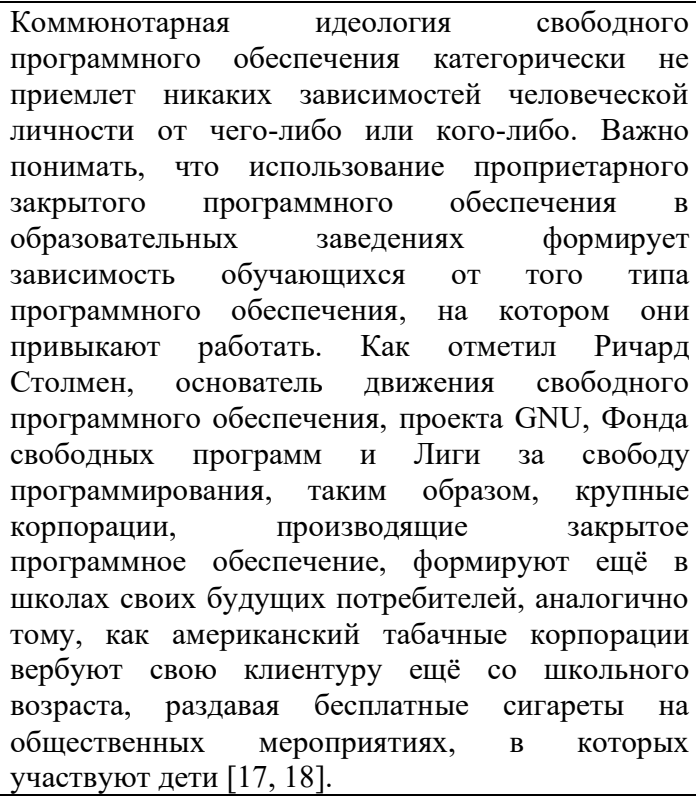 & $\begin{array}{l}\text { В данном случае речь идет о самом } \\
\text { важном условии, только при наличии } \\
\text { которого становится возможно } \\
\text { жизненное, личностное, а также } \\
\text { профессиональное самоопределение, } \\
\text { a именно о свободе выбора. При } \\
\text { отсутствии свободы от навязанного } \\
\text { обучающимся в образовательном } \\
\text { процессе стереотипа пользователя } \\
\text { проприетарного йостранного } \\
\text { программного обеспечения какое- } \\
\text { либо успешное формирование } \\
\text { компонентов нравственно-этической } \\
\text { культуры, жизненного и личностного } \\
\text { самоопределения в принципе } \\
\text { невозможна, так как несвободный, } \\
\text { зависимый человек не способен ни к } \\
\text { самоопределению, } \\
\text { саморазвитию. }\end{array}$ \\
\hline
\end{tabular}


Однако внедрение свободного программного обеспечения в отечественном образовательном процессе сдерживается по нескольким причинам [10]:

- недостаточный уровень компетенций обучающихся и узкий кругозор в области применения полнофункционального программного обеспечения вследствие повседневного и преимущественного использования обучающимися мобильных аппаратных средств в социальной и досуговой деятельности;

- недостаточная просветительская работа по популяризации использования свободного программного обеспечения для решения обучающимися учебных и социальных задач;

- наличие у обучающихся, особенно у детей и подростков, низкого порога восприятия риска совершения противоправных действий, антисоциального поведения, не полностью компенсируемый соответствующей разъяснительной работой, направленной на повышение правовой грамотности в области соблюдения авторского права.

Рассмотрим, как характерные свойства свободного программного обеспечения могут способствовать формированию компонентов нравственно-этической культуры, жизненного и личностного самоопределения обучающегося (таблица 1).

Анализ свойств свободного программного обеспечения позволил сформулировать возможные пути формирования нравственно-этической культуры, жизненного и личностного самоопределения обучающихся, базирующихся на решении задачи развития спектра умений и навыков, составляющих основу процесса нравственного и этического воспитания обучающихся, в частности: умений выделять нравственный аспект поведения и соотносить поступки и события с принятыми этическими принципами, навыков выбора предпочитаемой сферы профессиональной деятельности и установления профессионально-ориентированных контактов, навыков ориентации в социальных ролях и межличностных отношениях, построенных на основе сотрудничества и бескорыстной взаимопомощи.

\section{Выводы}

Идеология свободного программного обеспечения универсальна, опирается на систему общепринятых в российском обществе нравственных норм, не зависит ни от национальной, ни от культурной, ни от конфессиональной принадлежности конкретного обучающегося. В её основу положен принцип свободы, без усвоения которого само формирование компонентов нравственно-этической культуры вряд ли возможно, так как несвободный, зависимый человек не способен ни к самоопределению, ни к саморазвитию.

Авторы считают, что применение коммюнотарной, по терминологии Н.А. Бердяева, идеологии свободного программного обеспечения не только целесообразно, но и жизненно необходимо для успешного формирования компонентов нравственно-этической культуры, жизненного и личностного самоопределения у учащихся общеобразовательных школ (как основы для развития личностных универсальных учебных действий) и студентов высших учебных заведений.

Коммюнотарность сообщества свободного программного обеспечения способна оказать непосредственное влияние на атмосферу образовательного процесса, особенно в предметной области «Математика и информатика». Вряд ли кто-то способен поставить под сомнение, что профессиональное (и одновременно человеческое) общение преподавателя с обучающимися, построенное именно на основе искренности, взаимопонимания, свободы, идейного партнерства, общей цели, есть тот идеал педагогической деятельности, который может дать максимально возможное качество обучения в условиях современной российской школы и Вуза. 


\section{Литература}

[1] Федеральный закон «Об образовании в Российской Федерации». URL: https://rg.ru/2012/12/30/obrazovanie-dok.html (дата обращения 09.01.2020).

[2] Данилюк А.Я., Кондаков А.М., Тишков В.А. Концепция духовно-нравственного развития и воспитания личности гражданина России. М.: Просвещение, 2009. 23 с.

[3] Стратегия развития воспитания в Российской Федерации на период до 2025 года. URL: https://rg.ru/2015/06/08/vospitanie-dok.html (дата обращения 09.01.2020).

[4] Розина О.В. Подготовка учителя к формированию личностных универсальных учебных действий у учащихся на основе православных традиций и ценностей // Вестник ПСТГУ. Серия 4: Педагогика. Психология. 2013. № 4 (31). С. 26-39.

[5] Фундаментальное ядро содержания общего образования / Рос. акад. наук, Рос. акад. образования; под ред. В.В. Козлова, А.М. Кондакова. 4-е изд., дораб. М.: Просвещение, 2011. 79 с.

[6] Коммюнотарность. Философский словарь. URL: http://slovari-online.ru/word/ философский-словарь/коммюнотарность.htm (дата обращения 02.02.2020).

[7] Семигин Г.Ю. Новая философская энциклопедия : в 4 т./ пред. науч.-ред. Совета B.С. Стёпин. 2-е изд., испр. и доп. М.: Мысль, 2010. 2816 с.

[8] Бердяев, Н. О свободе и рабстве человека. М.: T8RUGRAM, 2018. 368 с.

[9] Федосов А.Ю., Маркушевич М.В Применение свободного программного обеспечения в учебном процессе как фактор духовно-нравственного воспитания учащихся // Информатика в школе. 2018. № 4 (137). С. 40-43.

[10]Федосов А.Ю., Маркушевич М.В Свободное программное обеспечение в образовательном процессе как фактор формирования правового и технологического аспектов информационной культуры школьника // International Journal of Open Information Technologies. 2020. T. 8, № 1. С. 79-89.

[11]Что такое свободная программа? Официальный сайт проекта GNU. URL: http://www.gnu.org/philosophy/free-sw.ru.html (дата обращения 09.01.2020).

[12]Несвободные программы часто вредоносны. Официальный сайт проекта GNU. URL: http://www.gnu.org/proprietary/proprietary.html (дата обращения 09.01.2020).

[13] Google pulls adblocking app for Samsung phones. Официальный сайт The Guardian. URL: https://www.theguardian.com/media/2016/feb/03/google-pulls-ad-blocking-app-forsamsung-phones (дата обращения 09.01.2020).

[14] Raphael Orlove. America Figured Out A New Way Audi Cheated on Emissions Testing: Report. URL: https://jalopnik.com/america-figured-out-a-new-way-audi-cheated-onemissions-1788630969 (дата обращения 09.01.2020).

[15] Ashley Carman. Samsung phones are spontaneously texting users' photos to random contacts without their. URL: https://www.theverge.com/circuitbreaker/2018/7/2/17528076/ samsung-phones-text-rcs-update-messages (дата обращения 09.01.2020).

[16] Peter Bright. New processors are now blocked from receiving updates on old Windows. URL: https://arstechnica.com/information-technology/2017/04/new-processors-are-nowblocked-from-receiving-updates-on-old-windows (дата обращения 09.01.2020).

[17] Tobacco companies tell kids: 'Don't smoke!' Сайт BBC. URL: http://www.bbc.co.uk/worldservice/sci_tech/features/health/tobaccotrial/usa.htm (дата обращения 09.01.2020).

[18] Ричард Столмен. Свободные программы в учебных заведениях. URL: http://www.gnu.org/education/edu-schools.html (дата обращения 09.01.2020). 


\title{
Influence of Community Ideology of Free Software on the Formation of Moral and Ethical Culture, Life and Personal Self-determination of the Trained
}

\author{
A.Yu.Fedosov ${ }^{1}$, M.V.Markushevich ${ }^{2}$ \\ ${ }^{1}$ Russian Social State University, ${ }^{2}$ School 1352, Moscow
}

The paper discusses the communitarian ideology of free software as a source for building the educational process aimed at solving the problems of life and personal self-determination of students, value-semantic orientation of students, orientation in social roles and interpersonal relationships, personal motivation for learning activities.

The authors substantiate the thesis that the basis for the formation of the components of moral and ethical culture, life and personal self-determination of a student can be the communitarian ideology of free software; the advantages of using free software in the educational process to solve the problems of spiritual and moral education are revealed.

The authors show the ways of forming a moral and ethical culture, life and personal selfdetermination of students: based on the analysis of the characteristic properties of free software, the possibilities of forming students' skills to highlight the moral aspect of behavior and correlate actions and events with accepted ethical principles, skills to choose the preferred field of professional activity are revealed and joining one or another professional community, orientation in social roles and interpersonal relationships, skills in choosing a tool for solving educational and professional problems and focus on cooperation and selfless mutual assistance to other students in their development and application.

Keywords: free software, communitarianism, moral and ethical culture, life self-determination, personal self-determination, motivation for learning activities

Reference for citation: Fedosov A.Yu., Markushevich M.V. Influence of community ideology of free software on the formation of moral and ethical culture, life and personal selfdetermination of the trained // Information Society: Education, Science, Culture and Technologies of the Future. Vol. 4 (Proceedings of the XXII International JointScientific Conference «Internet and Modern Society», IMS-2020, St. Petersburg, June 17-20, 2020). St. Petersburg: ITMO University, 2020. P. 92 - 100. DOI: 10.17586/2587-8557-2020-4-92-100

\section{Reference}

[1] Federal'nyj zakon «Ob obrazovanii v Rossijskoj Federacii». URL: https://rg.ru/2012/12/30/obrazovanie-dok.html (data obrashcheniya 09.01.2020). (in Russian).

[2] Danilyuk A.YA., Kondakov A.M., Tishkov V.A. Koncepciya duhovno-nravstvennogo razvitiya i vospitaniya lichnosti grazhdanina Rossii. M.: Prosveshchenie, 2009. 23 s. (in Russian).

[3] Strategiya razvitiya vospitaniya v Rossijskoj Federacii na period do 2025 goda. URL: https://rg.ru/2015/06/08/vospitanie-dok.html (data obrashcheniya 09.01.2020). (in Russian).

[4] Rozina O.V. Podgotovka uchitelya k formirovaniyu lichnostnyh universal'nyh uchebnyh dejstvij u uchashchihsya na osnove pravoslavnyh tradicij i cennostej // Vestnik PSTGU. Seriya 4: Pedagogika. Psihologiya. 2013. №4 (31). S. 26-39. (in Russian).

[5] Fundamental'noe yadro soderzhaniya obshchego obrazovaniya / Ros. akad. nauk, Ros. akad. obrazovaniya; pod red. V.V. Kozlova, A.M. Kondakova. 4-e izd., dorab. M.: Prosveshchenie, 2011. 79 s. (in Russian). 
[6] Kommyunotarnost'. Filosofskij slovar'. URL: http://slovari-online.ru/word/filosofskijslovar'/kommyunotarnost'.htm. (in Russian).

[7] Semigin G.YU. Novaya filosofskaya enciklopediya: v 4 t. / pred. nauch.-red. Soveta V.S. Styopin. 2-e izd., ispr. i dop. M.: Mysl', 2010. 2816 s. (in Russian).

[8] Berdyaev, N. O svobode i rabstve cheloveka. M.: T8RUGRAM, 2018. 368 s. (in Russian).

[9] Fedosov A.YU., Markushevich M.V Primenenie svobodnogo programmnogo obespecheniya $\mathrm{v}$ uchebnom processe kak faktor duhovno-nravstvennogo vospitaniya uchashchihsya // Informatika v shkole. 2018. № 4 (137). S. 40-43. (in Russian).

[10]Fedosov A.YU., Markushevich M.V Svobodnoe programmnoe obespechenie V obrazovatel'nom processe kak faktor formirovaniya pravovogo i tekhnologicheskogo aspektov informacionnoj kul'tury shkol'nika // International Journal of Open Information Technologies. 2020. T. 8, № 1. S. 79-89. (in Russian).

[11]CHto takoe svobodnaya programma? Oficial'nyj sajt proekta GNU. URL: http://www.gnu.org/philosophy/free-sw.ru.html (data obrashcheniya 09.01.2020). (in Russian).

[12] Nesvobodnye programmy chasto vredonosny. Oficial'nyj sajt proekta GNU. URL: http://www.gnu.org/proprietary/proprietary.html (data obrashcheniya 09.01.2020). (in Russian).

[13] Google pulls adblocking app for Samsung phones. Oficial'nyj sajt The Guardian. URL: https://www.theguardian.com/media/2016/feb/03/google-pulls-ad-blocking-app-forsamsung-phones (data obrashcheniya 09.01.2020). (in Russian).

[14]Raphael Orlove. America Figured Out A New Way Audi Cheated on Emissions Testing: Report. URL: https://jalopnik.com/america-figured-out-a-new-way-audi-cheated-onemissions-1788630969 (data obrashcheniya 09.01.2020).

[15] Ashley Carman. Samsung phones are spontaneously texting users' photos to random contacts without their. URL: https://www.theverge.com/circuitbreaker/ 2018/7/2/17528076/samsung-phones-text-rcs-update-messages (data obrashcheniya 09.01.2020).

[16] Peter Bright. New processors are now blocked from receiving updates on old Windows. URL: https://arstechnica.com/information-technology/2017/04/new-processors-are-nowblocked-from-receiving-updates-on-old-windows (data obrashcheniya 09.01.2020).

[17] Tobacco companies tell kids: 'Don't smoke!' Sajt BBC. URL: http://www.bbc.co.uk/worldservice/sci_tech/features/health/tobaccotrial/usa.htm (data obrashcheniya 09.01.2020).

[18]Richard Stolmen. Svobodnye programmy v uchebnyh zavedeniyah. URL: http://www.gnu.org/education/edu-schools.html (data obrashcheniya 09.01.2020). 